\title{
Unit of Mass Concentration
}

National Cancer Institute

\section{Source}

National Cancer Institute. Unit of Mass Concentration. NCI Thesaurus. Code C64571.

A concentration unit measured as the mass of solute per volume of mixture. 